\title{
A survey on effective assessment methods to enhance student learning
}

\author{
KN Le and VWY Tam ${ }^{+}$ \\ Griffith School of Engineering, Griffith University, Gold Coast, Queensland
}

\begin{abstract}
SUMMARY: The effectiveness of eight different assessment methods - (1) seminar, (2) closed-book mid semester test, (3) open-book mid-semester test, (4) problem-based assignment, (5) presentation, (6) multiple choice question test, (7) closed-book final examination, and (8) open-book final examination - is studied in this paper. A detailed survey is conducted to thoroughly understand student needs, and the significance of assessment items and methods. Individual interviews are conducted to gather further information and clarification on the survey. Relative important index (RII) values and F-tests of all categories and groups are estimated. Recommendations are given to improve the effectiveness of various assessment methods.
\end{abstract}

\section{INTRODUCTION}

Understanding student differences in their motivation, attitude about teaching and learning, and responses to different classroom environment and instructional practices helps lecturers meet the diverse student needs (Ribeiro \& Mizukami, 2005). While it is impossible to tailor their class to match each student's needs, it is possible to provide a balanced teaching approach that will meet the needs of the majority of the students in the classroom (Besterfield-Sacre et al, 2001).

One of the main student concerns is how to pass a course and, at the same time, achieving satisfaction. For example, for a particular course such as Physics, most students may consider a grade of Credit as satisfactory, however, a small number of students in the class may aim for High Distinction. As such, assessment items and methods, which tell students how to score marks contributing towards the final grade, play a key role. Further, achieving a high grade for a course, which means that students theoretically understand the subjects and concepts taught in the

* Paper D07-012 submitted 14/03/07; accepted for publication after review and revision 29/08/07. Both authors contributed equally to this paper.

† Corresponding author Dr Vivian Tam can be contacted at v.tam@griffith.edu.au. course, does not always mean that they are satisfied with the course. Students usually consider further explorations during their own time to apply the knowledge that they have learnt in the course to real-world problems, such as finding jobs, webpage design, designing a small circuitry or building a bridge meeting certain criteria. Thus, assessment items and methods need to be carefully designed and experimented with to meet student needs on one hand, and to ensure that they are able to contribute to their profession upon graduating on the other hand (Berglund et al, 1998). This can be considered as the single most important aspect of assessment. From the lecturer perspective, it should also be noted that assessment items and methods should also be designed and arranged so that the marking and feedback-giving processes are not time consuming. This ensures that the teaching process is productive, and by meeting the above-mentioned point, the teaching process can be considered effective and satisfactory (Hapburn, 1992).

The most effective way to measure the effectiveness of assessment items and methods is to conduct surveys to measure student attitude (Berglund et al, 1998; Burtner, 2005; Carrington et al, 2005; Grace et al, 1998; Mead et al, 1999; Ribeiro \& Mizukami, 2005). From that, possible improvements can be made. The objectives of this paper are:

- To conduct student attitude and understanding on different assessments items and methods. 
- To show and to analyse results of the survey using RII values and F-tests results.

- To give appropriate recommendations to improve the assessment methods.

\section{2}

\section{LEARNING APPROACH}

Learning is a succession of (Griffith Institute For Higher Education, 2006): i) an increase in knowledge; ii) memorising; iii) acquisition of facts and procedures; iv) abstraction of meaning; and v) an interpretive process. Two conceptions can be linked to approaches to learning that have been classified as taking a surface or deep approach by Gibbs's study (Gibbs, 1992). Figure 1 shows a 3 "P" model of teaching and learning, which involves Presage, Process and Product. Process is the main focus in this paper, in which it can be divided into two main learning approaches: a deep approach and a surface approach. In the deep approach, students attempt to make sense of what is to be learnt, which consists of ideas and concepts. This involves integrating between components and between tasks, and also playing with ideas. In the surface approach, students reduce what is to be learnt to the status of unconnected facts to be memorised. The learning task is to reproduce the subject matter at a later date.

The surface approach to learning is encouraged by (Ramsden, 2003): i) assessment methods emphasising recall or unconceptualised procedural knowledge; ii) assessment methods that create anxiety; iii) cynical or conflicting messages about rewards; iv) an excessive amount of material in the curriculum; v) poor or no feedback on progress; vi) lack of independence in studying; and vii) lack of interest and background knowledge in the subject matter.
The deep approach to learning is encouraged by (Ramsden, 2003): i) methods that foster active and long term engagement with learning; ii) stimulating and considerate teaching; iii) clearly-stated academic expectations; iv) appropriate and timely feedback; v) opportunities to exercise responsible choices in the method and content of study; and vi) interests in background knowledge of the subject matter.

Teaching that encourages students to develop the deep approach to learning has the following characteristics (Griffith Institute For Higher Education, 2006): i) supports independent learning; ii) organises appropriate learning activities; iii) encourages interaction with others; and iv) uses appropriate assessment practices that reward deep learning and informs students in advance of the required criteria and standards.

\section{RESEARCH METHODOLOGY}

To examine student attitude and understanding toward different assessment methods, a survey has been conducted. The survey was sent to 200 undergraduate engineering students, of which 64 responses have been received, which is a response rate of $32 \%$.

The degree programs that the responding students were undertaking are: 57 from Bachelor of Engineering, 1 from Bachelor of Engineering Technology; 2 from the Bachelor of Engineering and Bachelor of Business double-degree program; 2 from the Bachelor of Engineering and Bachelor of Information Technology double-degree program; and 2 from the Bachelor of Engineering and Bachelor of Environmental Science double-degree program.

\section{PRESAGE \\ PROCESS \\ PRODUCT}

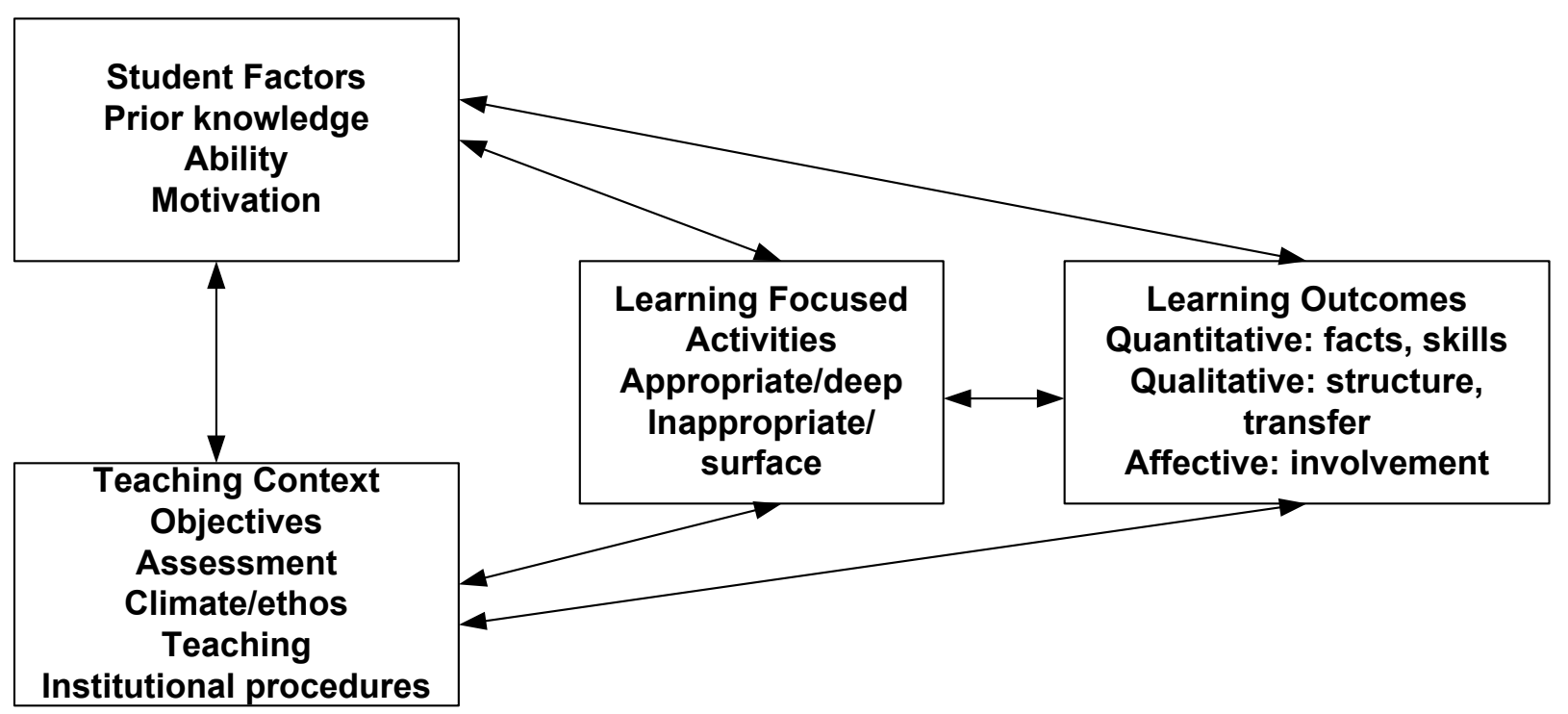

Figure 1: The 3 "P" model of teaching and learning (Griffith Institute For Higher Education, 2006). 
The majority of the responding students are in the third year of their degree program, 8 from the fourth year, 6 from the second year and 1 from the first year. More than $90 \%$ of the responding students (corresponding to 58 students) are male and 6 are female. All the responding students are in the age range between 19 and 31 . The percentages of the responding students in the age group of 19,20 and 21 are about 27\%,16\% and 20\%, respectively. About $80 \%$ of the total number of students in most Australian universities, including Griffith University, are local students who reside in Australia. Out of the responding students, 53 are local students, 3 from Africa, 4 from Asia and 4 from the Middle East.

The students were asked to rank different assessment methods on their attitude and understanding in helping them to fulfil their study needs and learning process. Each assessment method is given a weighting factor by the students ranging from 1 to 5 , in which " 1 " is the least important and " 5 " the most important. Eight assessment methods typically used at Griffith University are given in the survey: (1) seminar, (2) closed-book mid semester test, (3) open-book mid semester test, (4) problem-based assignment, (5) presentation, (6) multiple-choice question test, (7) closed-book final examination, and (8) open-book final examination.

There are five major categories in the survey: (i) Degree program, (ii) Degree level, (iii) Gender, (iv) Age, and (v) Ethnicity. Each category is divided into different groups that can then be analysed using a statistical software package. For the Degree program category, there are five major groups: (1) Bachelor of Engineering, (2) Bachelor of Engineering Technology, (3) Bachelor of Engineering and Bachelor of Business double-degree program, (4) Bachelor of Engineering and Bachelor of Information Technology doubledegree program, and (5) Bachelor of Engineering and Bachelor of Environmental Science double-degree program.

For the Degree level category, there are four major yearly groups: (1) First, (2) Second, (3) Third, and (4) Fourth. For the Gender category, there are two groups: (1) Male, and (2) Female. For the Age category, there are 11 groups: (1) 19, (2) 20, (3) 21, (4) 22, (5) 23, (6) 24, (7) $25,(8) 26,(9) 29,(10) 30$, and (11) 31. The Ethnicity category has four major groups: (1) Australian, (2) African, (3) Asian, and (4) Middle East.

The data collected from the survey are analysed using the Statistical Package for Social Sciences (SPSS) Version 14.0 for Windows. The mean values of the data are numerically estimated, and tested among the groups. F-tests are performed with a demarcation level of significance of 0.05 . The tests are used to assess the similarity of opinion among the groups on the assessment methods given in the survey.

To determine the relative ranking of the assessment methods, the scores entered in the survey by students are transformed to RII values using equation (1) (Tam et al, 2000):

$R I I=\frac{\sum w}{A N}$

where $w$ is the weighting given to each factor by the responding students, ranging from 1 to $5, A$ is the highest weight (ie. 5 for this study), $N$ is the total number of samples, and RII is the relative important index, $0 \leq \mathrm{RII} \leq 1$.

After collecting the survey, individual interviews were arranged with 10 responding students which are chosen to represent each category and the various groups defined above. The interviews were intended to gather further comments, elaboration and interpretation on the results obtained from the survey.

It should be noted that this paper has been written from a student point of view on various assessment methods. Because the interviewed students are ranging from first year to fourth year, it is difficult to objectively assess the assessment methods, which involves specific student grouping and objective assessment. By using the RII, it is possible to quantitatively analyse the student view on the assessment methods, from that, it is possible to obtain guidance on how to improve their effectiveness and student learning. Even though student view is sometimes divergent, it is believed that the detailed quantitative measures presented in this paper are sufficient to draw initial conclusions on the assessment methods. Objective measures on these methods can then be conducted later to validate the quantitative results obtained based on student view.

\section{$4 \quad$ RESULTS AND DISCUSSIONS}

From the F-test results, items with the level of significance lower than 0.05 are considered to be significant. To enhance student understanding, between the gender groups, there is a significant difference for the problem-based assignment assessment method. The overall mean value obtained using the F-test is about 3.7, with the mean value of the Male and Female groups of about 3.62 and 4.5 , respectively. This means that the Female group considered this assessment item as significant for their understanding of the course, whereas the Male group did not have the same view. The reason for this is because the Male group considered themselves as having better engineering knowledge than the Female group, therefore, problem-based learning might not be appealing to them. Instead, according to one of the responding students, the Male group would look for real-life problem-based assessment methods, such as bridge designing meeting certain criteria, cost analysis based on project performance and budget 
management of construction projects. In contrast, the Female group considered themselves to be the minority group in the male-dominated profession, therefore, they are prepared to work hard to catch up with their male colleagues in the profession. This is one major factor motivating the Female group to prefer this particular assessment method. It should be noted that the students were asked to introduce themselves at the beginning of the course and, more importantly, indicate whether they have professional work experience. Most male students showed strong practical experience than female students, which leads to the conclusion that male students are experience-oriented for this particular course in this particular year. However, this is not generally the case for any course in any year.

Under the Age category, to enhance student attitude, for the closed-book mid semester test, the overall mean value is about 3.41 , and the mean values of the 11 groups are about 2.88, 3.60, 3.85, 3.11, 4.25, 3.50, 4.00, $4.50,3.00,3.00$ and 2.50, respectively, which shows that for the Age group of 31, this assessment method is not beneficial. This can be explained as the students in the Age group of 31 are mostly independent and would prefer to spend more time on their independent and individual study. The Age groups of 23 and 26 have the largest means values of about 4.25 and 4.5, respectively, which means that they prefer this particular assessment method. From the individual interviews in these particular Age groups, the majority of students were at that time looking for employment and working part-time, therefore, they would prefer more assessment items during the semester to improve their final grades.

The RII values of all assessment methods are shown in table 1 and plotted in figure 2 . The RII values are used to rank the assessment methods to enhance student attitude and understanding. The problembased assignment, multiple-choice question test and open-book final examination are ranked first to enhance student attitude assessment methods because they are directly related to what the students have learnt in the class. The presentation assessment method is ranked last as most students are not very familiar with this style of assessment. From the interviews with the responding students, most students even considered this assessment method as time wasting. Another reason why this assessment method is ranked last is because it normally carries only $10 \%$ of the total mark in most courses at Griffith University.

For facilitating understanding, problem-based assignment, open-book and closed-book final examination assessment methods are ranked first, second and third, respectively. It is clear that these assessment methods are directly related to what students have learnt in class. From the interviews with the responding students, problembased assignments helped improve their knowledge on particular subjects and concepts taught in the course. The open-book final examination rather than the closed-book final examination is preferred because there are usually many practical details and fact sheets that students need to master before sitting the exam. Having an open-book final examination eases the pressure of memorising these sheets, and also gives the benefits of bringing necessary books and notes to the examination. One drawback from the open-book final examination is that it is harder than the closed-book final examination. Despite this fact, the open-book final examination is still an effective assessment method from the student point of view.

From table 1, it should be noted that the presentation and problem-based assignment assessment methods are ranked last and first, respectively, to enhance student attitude and understanding assessment due to the reason explained earlier. The problem-based assignment assessment method is usually preferred over other assessment methods because of its direct relationship to student knowledge and learning. The presentation and seminar methods usually involve either the surface approach or the deep approach, or both. For the first case, the surface approach is usually not strongly related to the course content and usually carries a small amount of marks. Therefore, students do not want to pay too much attention on this particular assessment item. For the second case,

Table 1: Assessment methods to enhance students attitudes and understanding.

\begin{tabular}{|l|c|c|c|c|}
\hline \multirow{2}{*}{ Assessment method } & \multicolumn{2}{|c|}{ To enhance student attitude } & \multicolumn{2}{c|}{$\begin{array}{c}\text { To enhance student } \\
\text { understanding }\end{array}$} \\
\cline { 2 - 5 } & RII value & Ranking & RII value & Ranking \\
\hline Seminar & 0.59 & 7 & 0.58 & 7 \\
\hline Closed-book mid-semester test & 0.68 & 5 & 0.68 & 5 \\
\hline Open-book mid-semester test & 0.72 & 4 & 0.69 & 3 \\
\hline Problem-based assignment & 0.74 & 1 & 0.74 & 1 \\
\hline Presentation & 0.49 & 8 & 0.53 & 8 \\
\hline Multiple-choice question test & 0.74 & 1 & 0.66 & 6 \\
\hline Closed-book final examination & 0.66 & 6 & 0.69 & 3 \\
\hline Open-book final examination & 0.74 & 1 & 0.70 & 2 \\
\hline
\end{tabular}


the assessment items involve the deep approach to learning and, therefore, is more complicated than the first case. The third case is considered to be the most complicated with both surface and deep approaches. An example of the first case is an introductory seminar presentation. An example for the second and third cases is final-year thesis seminars, which usually combine deep- and surface-approach learning. In addition, students are also required to possess effective communication skills to achieve a satisfactory score for this assessment item. From the interview with the responding students, most students admitted that they did not possess effective communication skills and the deep approach to learning in the presentation and seminar assessment methods is challenging.

To make students more committed to weaker assessment methods, such as seminar and presentation, an obvious option would be to assign more marks to these methods, which motivate students to pay more attention and efforts. In addition, seminar and presentation methods, even though being considered as "weak" from the student point of view, are believed to play major roles in shaping student thinking and understanding on a particular topic in the course. This is of significant important when students enter the work force because there are no examinations or written tests in the industry, and they must work in a team to professionally present their findings to their workmates. It should be stressed that the students ranked assessment items from "weak" to "strong" depending on the associated marks allocated to the assessment, as the main goal of most students is to pass the course and be able to successfully finish their degree. Thus by assigning more marks to "weak" assessment methods, it is possible to make them "stronger" from the student point of view, which attracts more attention. For example, a final examination can be considered as a deep learning approach, which requires student understanding and logical thinking to obtain a pass. The students highly rated this assessment method because it simply carries the most marks toward the final grade, not because of the type of learning approach it possesses. Thus, by paying attention and efforts to the exam preparation, it is likely that students can gain sufficient knowledge and understanding on the relevant topics of the course and hence achieving a satisfactory grade. It should also be noted that the exam preparation process usually involves hard work and most students, even the committed ones, do not entirely enjoy it even though they expressed that they have learnt a lot in the process. Again, it is clear that the main goal is to achieve a satisfactory grade for the course and, while doing that, students gain the necessary knowledge and understanding on the course by means of the assessment methods designed by the lecturer.

To balance between deep and surface learning approaches, weekly assignments of different depth and contents can be employed. A "surface" assignment usually requires students to apply wellknown formulas given in class to a number of simple problems. To make it even more interesting, students are then asked to plot or simulate the relationships among these problems. It is also believed that graphical

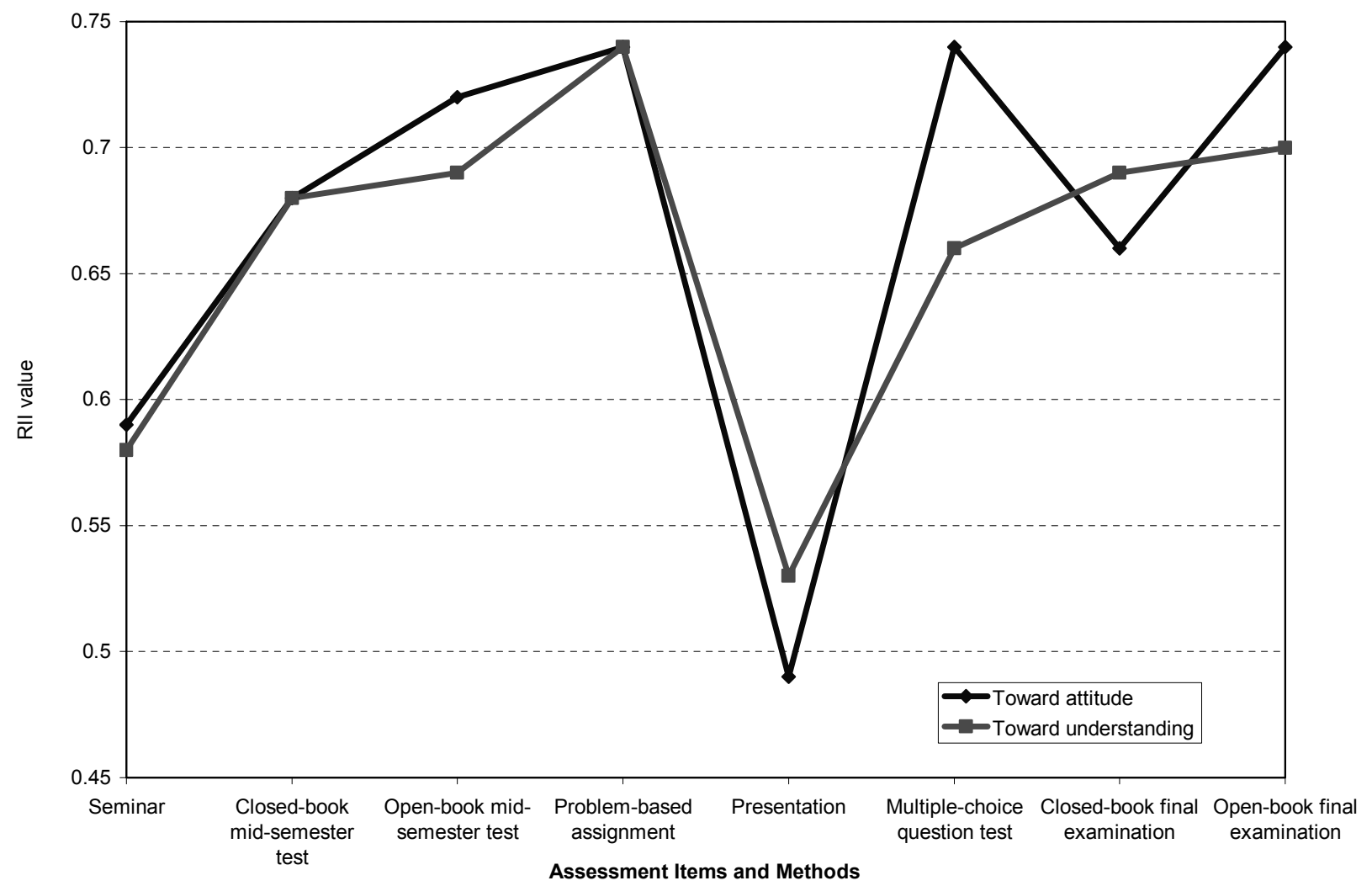

Figure 2: $\quad$ RII values of different assessment items and methods. 
simulations can stimulate student motivation, thinking and understanding. This approach can hence be considered as a modified "surface" approach. After students successfully completed the surface assignment, the next assignment is designed to draw out possible conclusions from the first one and encourages students to think of typical cases where these conclusions can be used. The second "deep" assignment thus involves (i) conclusions on known results; and (ii) group discussions and debate that bring fruitful understanding on a particular topic of the course. For one semester of about 13 weeks, maximum three pairs of "surface""deep" assignments can be employed to achieve the optimal balance between surface and deep learning approaches. However, the number of students in the class also plays an important factor, as the more students in the class, the harder it is to implement this learning style.

A question one may ask at this point is: "Why try to balance deep and surface learning approaches?", as the latter is not usually recommended at university levels. As noted above, student learning approach can be considered as having two significant phases: (i) surface and (ii) deep. The surface learning approach initiates and motivates students to learn on a particular topic by giving them simple, yet important, problems to solve rather than memory-testing. These problems thus form a foundation in student minds, signifying typical phenomena or behaviour when a particular topic is discussed. For example, a topic on construction industry would bring to student minds a question: "How many tons of waste are generated every day in southeast Queensland?". Given the population of the region, it is possible to estimate the amount of waste per person. To complete this assignment, students were asked to estimate the above required quantity. The second phase of the learning process is to initiate deep learning approach based on what students have learnt and estimated from the first phase. The second assignment can thus be written as: "By knowing the amount of waste generated per person in southeast Queensland, is it possible to devise a number of strategies that can lower this number? The strategies can be dependent on environmental conditions, population growth, geography and weather patterns." It is clear now that at this point in the student learning process, they have not encountered new terms such as "geography" and "environmental conditions", and, more importantly, their relationships to waste generation. To help students with their learning, the lecturer can then allow them ample time of about 1 to 2 weeks to conduct a mini research on this particular topic. Students then discuss their findings and initiate group debating to defend their ideas. This also shows the effectiveness of the presentation and seminar assessment methods, which are usually "ignored" by students because they carry a smaller amount of marks than other assessment methods. Thus, in a long term, the surface learning approach can positively contribute to the student learning process by motivating and stimulating their interests.

\section{RECOMMENDATIONS}

According to the findings in this paper, problem-based learning is the most effective assessment method from the student point of view. Thus, to improve the teaching and learning processes, the following items are recommended:

- Enhance student understanding by arranging more problem-based sessions in class. The style of problem-based learning can also be varied by giving students a current topic of interest and initiating debate. Real-world case studies are also encouraged.

- Inviting guest lecturers to give lectures on reallife experience on particular issues in industry, which is usually lacking in the academic environment.

- Encourage students to be familiar with presentation and seminar assessment methods, and to ensure they understand that these methods are very common in the work force. These methods can also be used to greatly improve student communications skills and public speaking confidence.

- Assigning more marks toward other weaker assessment methods outlined in table 1 , such as closed-book and open-book mid-semester tests, to achieve the balance among all assessment methods in the course.

- Balancing assessment items on the deep- and the surface-learning approaches to suit different student learning styles.

\section{CONCLUSION}

A survey on different assessment methods to enhance student attitude and understanding has been conducted. Five categories with different numbers of groups have been classified and studied in this paper. The relative important index (RII) and the overall mean values of all groups under each category have been estimated. From the numerical results, it has been found that the problem-based assignment assessment method is the most effective method from the student point of view to enhance student attitude and understanding. The worst assessment methods were presentation and seminar because they are not directly related to student's needs and knowledge. Individual interviews with responding students have also been conducted to more thoroughly understand student needs and to improve their learning process. Useful recommendations have also been suggested to further improve the effectiveness of different assessment methods. 


\section{ACKNOWLEDGEMENTS}

The authors would like to thank the anonymous reviewers for their constructive comments, which have greatly improved the paper quality and clarity.

\section{REFERENCES}

Berglund, A., Daniels, M., Hedenborg, M. \& Tengstrand A. 1998, "Assessment to increase students' creativity: two case studies", European Journal of Engineering Education, Vol. 23, No. 1, pp. 45-54.

Besterfield-Sacre, M., Moreno, M., Shuman, L. J. \& Atman, C. J. 2001, “Gender and ethnicity differences in freshman engineering student attitudes: a crossinstitutional study", Journal of Engineering Education, Vol. 90, No. 4, pp. 477-489.

Burtner, J. 2005, "The use of discriminate analysis to investigate the influence of non-cognitive factors on engineering school persistence", Journal of Engineering Education, Vol. 94, No. 3, pp. 335-338.

Carrington, D., Strooper, P., Newby, S. \& Stevenson, T. 2005, "An industry/university collaboration to upgrade software engineering knowledge and skills in industry", The Journal of Systems and Software, Vol. 75, No. 1-2, pp. 29-39.

Gibbs, G. 1992, Improving the quality of student learning through course design. Learning to effect, The Society for Research into Higher Education, Buckingham, Great Britain, Open University Press.
Grace, G. G., Massay, L. \& Udoka, S. J. 1998, “Total quality systems: using a multidisciplinary preparation course for teaching quality improvement", Computers and Industrial Engineering, Vol. 35, No. 1-2, pp. 249253.

Griffith Institute For Higher Education, 2006, Certificate of higher education, Griffith Institute For Higher Education, Griffith University.

Hapburn, B. 1992, "Graduates into engineering: attitudes and intentions of final-year undergraduate engineers", Education and Training, Vol. 34, No. 4, pp. 20-26.

Mead, N., Bechman, K., Lawrence, J., O'Mary, G., Parish, C., Unpingco, P. \& Walker, H. 1999, "Industry/university collaborations: different perspectives heighten mutual opportunities", The Journal of Systems and Software, Vol. 49, No. 2-3, pp. $155-162$.

Ramsden, P. 2003, Learning to teach in higher education, Taylor and Francis Inc..

Ribeiro, L. R. C. \& Mizukami, M. G. N. 2005, "Problem-based learning: a student evaluation of an implementation in postgraduate engineering education", European Journal of Engineering Education, Vol. 30, No. 1, pp. 137-149.

Tam, C. M., Deng, Z. M., Zeng, S. X. \& Ho, C. S. 2000, "Quest for continuous quality improvement for public housing construction in Hong Kong", Journal of Construction Management and Economics, Vol. 18, No. 4, pp. 437-446. 

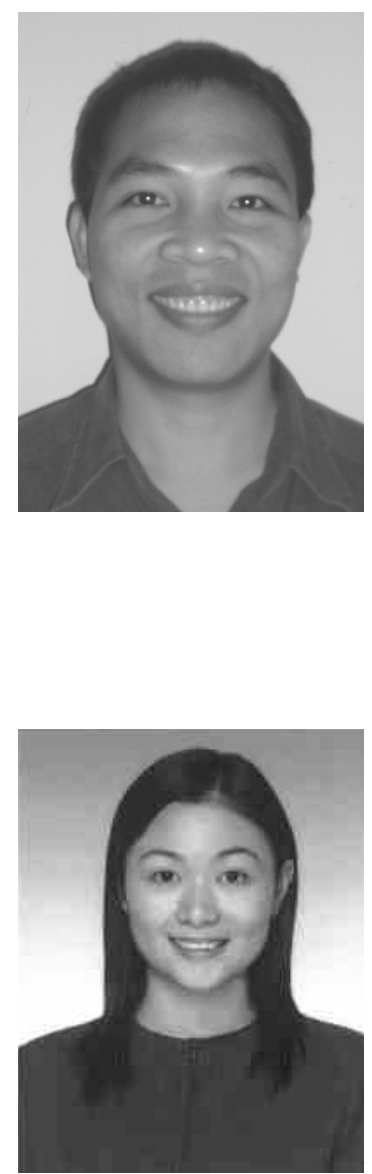

\section{KHOA LE}

Dr Khoa N Le is a lecturer at the Griffith School of Engineering, Griffith University, Gold Coast campus. Khoa received his PhD in October 2002 from Monash University, Melbourne. From 2002 to 2003, he was a research associate at the university, conducting research and teaching in signal processing and telecommunications at the Department of Electrical and Computer Systems Engineering. His research interests are in image processing, chaos, wavelets with applications, and wireless communications.

\section{VIVIAN TAM}

Dr Vivian WY Tam is a lecturer at the Griffith School of Engineering, Griffith University. Vivian received her $\mathrm{PhD}$ in recycling concrete waste from the Department of Building and Construction at the City University of Hong Kong in 2005. She has been developing her research interests in the areas of engineering education, environmental management in construction and sustainable development. She has published more than 100 peer-reviewed articles in leading journals and conferences. She is also an invited member of Editorial Advisory Board for Construction and Building Materials. 